\title{
PENGARUH KEPUASAN KERJA DAN KETERIKATAN KARYAWAN TERHADAP TURNOVER INTENTION KARYAWAN (STUDI KASUS: RESTORAN)
}

\author{
THE EFFECT OF JOB SATISFACTION AND EMPLOYEE ENGAGEMENT ON TURNOVER INTENTIONS \\ (CASE STUDY: RESTAURANT)
}

\author{
Atika Permata Sari*), Aji Hermawan*), dan M. Joko Affandi**) \\ ${ }^{*}$ Sekolah Bisnis, IPB University \\ Jl. Raya Pajajaran Bogor 16151, Indonesia \\ ${ }^{* *}$ PPM Jakarta \\ Jl. Menteng Raya No.9, Daerah Khusus Ibukota Jakarta 10340, Indonesia
}

\begin{abstract}
Karimata is a restaurant that has two branches at Taman Mini Indonesia Indah (TMII), Jakarta and Sentul, Bogor. Even though they are in the same management, both of them have different turnover rates. The average annual turnover at TMII is higher than in Sentul. The purpose of this study was to examine job satisfaction, employee involvement and turnover intentions in both Karimata restaurant locations to reduce turnover rates. The method used is quantitative analysis. The data used is primary data which obtained through filling out questionnaires directly to all permanent employees. Data were collected by census method. The data were analyzed by SEM (Structural Equation Modeling) using SmartPLS software. This study concludes that indicators that affect job satisfaction in TMII are tasks, promotion opportunities, and colleagues, while Sentul branches are salaries, assignments, promotion opportunities, supervisors, and colleagues. The indicator that influences employee involvement in TMII is sincerity and dedication, while in Sentul is dedication. The indicator that influences turnover intentions in TMII is the intention to leave, while in Sentul there is no indication of employees who intend to leave, look for other jobs or think of quitting.
\end{abstract}

Keywords: employee engagement, job satisfaction, restaurant, SEM, turnover intention

\begin{abstract}
Abstrak: Karimata adalah nama restoran yang memiliki dua cabang di Taman Mini Indonesia Indah (TMII), Jakarta dan Sentul, Bogor. Meskipun, mereka berada dalam manajemen yang sama, keduanya memiliki tingkat turnover yang berbeda. Omset ratarata per tahun di TMII lebih tinggi daripada di Sentul. Tujuan dari penelitian ini adalah untuk menguji kepuasan kerja, keterlibatan karyawan dan niat turnover di kedua lokasi restoran Karimata untuk mengurangi tingkat turnover. Metode yang digunakan adalah kuantitatif. Data yang digunakan berupa data primer yang diperoleh melalui pengisian kuesioner secara langsung kepada seluruh karyawan tetap. Pengambilan data dilakukan dengan metode sensus. Data dianalisis dengan SEM (Structural Equation Modeling) PLS menggunakan software SmartPLS. Penelitian ini menyimpulkan bahwa indikator yang mempengaruhi kepuasan kerja di TMII adalah tugas, peluang promosi, dan kolega, sedangkan cabang Sentul adalah gaji, tugas, peluang promosi, pengawas, dan kolega. Indikator yang memengaruhi keterlibatan karyawan di TMII adalah ketulusan dan dedikasi, sedangkan di Sentul adalah dedikasi. Indikator yang berpengaruh pada intensi turnover di TMII adalah niat untuk pergi, sedangkan di Sentul tidak ada indikasi karyawan yang berniat untuk pergi, mencari pekerjaan lain atau berpikir untuk berhenti.
\end{abstract}

Kata kunci: employee engagement, job satisfaction, restoran, SEM, turnover intention

${ }^{1}$ Corresponding author:

Email: permatasari.atika@gmail.com 


\section{PENDAHULUAN}

Kuliner merupakan salah satu bisnis yang cepat berkembang. Jumlah restoran yang cukup banyak memainkan peran penting dalam meningkatkan perekonomian nasional. Kontribusi sektor restoran dan perhotelan menempati urutan kedua setelah sektor perdagangan. Pertumbuhan bisnis restoran dan cafe terjadi sangat pesat, khususnya di kota besar seperti Jakarta. Jumlah industri kuliner di Jakarta mencapai 720 restoran pada tahun 2007 dan terus meningkat hingga mencapai 1361 restoran di tahun 2014 (BPS, 2015). Perkembangan industri kuliner tidak hanya terjadi di Jakarta, melainkan juga dapat terjadi pada berbagai wilayah lainnya. Data BPS memerlihatkan, jumlah rumah makan di Jawa Barat terus meningkat sejak tahun 2007 hingga tahun 2016. Jumlah restoran tertinggi di wilayah Jawa Barat terdapat di Bandung, yakni sebanyak 758 buah. Wilayah kedua tertinggi adalah Bogor, yakni mencapai 324 buah (Kemenpar Jabar, 2016). Bogor menjadi destinasi wisata warga ibukota karena lokasinya dekat, memiliki lingkungan dan udara yang lebih asri, serta didukung dengan destinasi wisata yang cukup banyak.

Keberhasilan sebuah restoran dalam bertahan menghadapi tekanan persaingan dari kompetitornya ditandai dengan konsistensi produk dan pelayanan yang diberikan. Untuk mencapai hal tersebut, sumberdaya manusia menjadi aset vital dalam menunjang keberhasilandan keberlanjutan(Alam, 2010). Karyawan merupakan sumber daya yang unik dan kompleks karena wujudnya terlihat secara fisik, namun bentuk sumber daya yang diberikan bersifat intangible yaitu berupa kemampuan, keahlian, pengetahuan, ataupun rasa loyalitasnya kepada perusahaan. Manajemen perlu menganggap karyawan sebagai aset, bukan beban, dan bertujuan untuk menciptakan dan memelihara tenaga kerja terampil dan berkomitmen tinggi untuk meraih keuntungan kompetitif (Muhyi et al. 2016).

Kontribusi dan kinerja karyawan dalam usaha memajukan restoran dapat dinilai melalui pengukuran job satisfaction. Sementara itu, jika karyawan memiliki rasa keterkaitan (engage) yang tinggi, maka akan meningkatkan perilaku umum, salah satunya tetap tinggal di perusahaan (Baumruk dan Gorman 2006). Hal ini berarti karyawan akan tetap bekerja di organisasi walaupun ada peluang untuk bekerja di tempat lain. Karyawan yang engaged akan memiliki keinginan untuk terikat yang menimbulkan gairah terhadap pekerjaanya, bersedia untuk mengorbankan lebih banyak tenaga dan waktu demi pekerjaannya, dan menjadi lebih proaktif dalam mencapai tujuan pekerjaannya (Macey et al. 2009). Salah satu bentuk perilaku kepuasan kerja yang diberikan adalah adanya katerikatan (engagement). Keterkaitan karyawan secara statistik memiliki korelasi dengan produktivitas, keuntungan, keamanan, retensi karyawan dan kepuasan pelanggan (Buckingham and Coffman, 2005). Karyawan yang memiliki engagement yang tinggi juga akan termotivasi untuk meningkatkan produktivitasnya, mau menerima tantangan dan merasa pekerjaannya memberi makna bagi dirinya. Hal tersebut akan berdampak positif terhadap kinerja karyawan, produktivitas dan pertumbuhan perusahaan. Maka dapat dikatakan, keterikatan kerja karyawan dapat memberikan perubahan bagi individu, tim dan organisasi (Margaretha dan Saragih, 2008). Engagement lainnya menurut Schaufeli et al. (2002) adalah hal yang positif, penuh makna, dan motivasi yang dicirikan melalui vigor, dedication, dan absorption.

Penelitian menunjukan kepuasan kerja yang tinggi berakibat pada tingkat turnover yang rendah (Mangkunegara, 2013). Ketika karyawan merasakan penurunan rasa semangat dan antusias karena kelelahan, mereka akan cenderung tidak menyukai pekerjaannya dan menjadi aktif untuk melihat kesempatan kerja di perusahaan lain (peningkatan turnover intention) (Siddiqi, 2013). Dalam hal ini, fenomena turnover akan menjadi masalah bagi restoran apabila karyawan berprestasi tinggilah yang keluar perusahaan dari perusahaan. Untuk menghindari hal tersebut perusahaan dapat mendeteksi sejak awal adanya keinginan karyawan untuk meninggalkan perusahaan (turnover intention). Menurut Yamazakia and Petchdee (2015), turnover intention menjadi prediksi terkuat yang melandasi pemikiran karyawan sebelum karyawan tersebut memutuskan untuk keluar dari perusahaan. Tingginya tingkat turnover telah menjadi masalah serius bagi banyak perusahaan.

Penelitian ini mengacu pada penelitian-penelitian terdahulu yang memiliki kesamaan dalam meneliti pengaruh kepuasan kerja dan keterikatan karyawan terhadap intensi keluar. Hasil penelitian Alam et al. (2013) yang menyatakan bahwa karyawan yang merasa puas dengan apa yang didapatkannya dari perusahaan maka akan bertahan untuk bekerja di perusahaan. Menurut hasil penelitian Rachmatan 
dan Kubatini (2018) pun menyatakan semakin tinggi tingkat work engagement karyawan maka semakin rendah tingkat intensi keluar. Penelitian ini memiliki beberapa perbedaan dengan penelitian yang terdahulu seperti lokasi penelitian yang membandingkan hasil di dua objek penelitian, yaitu di dua lokasi restoran serta metoda pengambilan data yang menggunakan sensus dimana saat ini belum terdapat penelitian sebelumnya yang meneliti di dua lokasi menggunakan metoda tersebut. Beberapa penelitian sebelumnya mengenai turnover intention dengan kepuasan kerja di restoran juga masih jarang dihubungkan dengan keterikatan karyawan yang mungkin menjadi akar dari kenapa turnover menjadi tinggi.

Pada penelitian ini akan dibandingkan pengaruh kepuasan kerja dan keterikatan karyawan terhadap intensi keluar di dua lokasi penelitian, yaitu Restoran Karimata di Taman Mini Indonesia Indah (TMII), Jakarta dan di Sentul, Bogor. Hal ini dikarenakan meskipun berada dalam satu manajemen, kedua cabang restoran ini memiliki tingkat turnover yang berbeda. Jumlah turnover rata-rata per tahun di cabang TMII lebih besar dibandingkan dengan di Sentul dimana pada tahun 2016 dan 2017 mencapai lebih dari $14 \%$ per tahun. Roseman (1981) menyebutkan bahwa tingkat turnover perusahaan dikategorikan tinggi jika melebihi angka 10\%. Sebelum turnover terjadi, ada tahap turnover intention atau keinginan berpindah dari satu tempat kerja ke tempat kerja lainnya. Pendekatan penyelesaian masalah di Restoran Karimata dapat dimulai dari mengkaji seberapa besar kepuasan karyawan (job satisfaction) dan employee engagement terhadap perusahaan. Selanjutnya, akan dievaluasi pengaruhnya terhadap turnover intention karyawan yang dibandingkan di kedua lokasi. Hal ini perlu dilakukan demi tercapainya menyetarakan dan peningkatan kualitas pelayanan. Oleh karena itu, tujuan dari penelitian ini yaitu diantaranya melakukan analisis perbedaan tingkat kepuasan kerja, keterikatan karyawan, dan intensi keluar; menganalisis indikator yang berkontribusi signifikan terhadap kepuasan kerja, keterikatan karyawan, dan intensi keluar; dan menganalisis pengaruh kepuasan kerja terhadap keterikatan karyawan, kepuasan kerja terhadap intensi keluar, dan keterikatan karyawan terhadap intensi keluar. Di samping itu, memberikan rekomendasi untuk menghilangkan/mengurangi intensi keluar di Restoran Karimata cabang TMII dan Sentul.

\section{METODE PENELITIAN}

Pengambilan data penelitian dilakukan di dua cabang Restoran Karimata yang terletak di Taman Mini Indonesia Indah (TMII), Jakarta dan Sentul, Bogor dimulai sejak bulan Maret 2019 hingga Mei 2019. Jenis data yang digunakan berupa data primer dan data sekunder. Data primer diperoleh melalui penyebaran kuesioner.Datasekunderberasaldariinternalperusahaan dan studi literatur dari berbagai sumber yang relevan. Metoda pengambilan data adalah sensus dimana semua karyawan tetap restoran Karimata di TMII dan Sentul menjadi responden penelitian. Jumlah keseluruhan karyawan adalah 116 orang, yang terbagi menjadi 59 karyawan TMII dan 57 karyawan Sentul. Penelitian ini menggunakan analisis kuantitatif dengan pendekatan SEM (Stuctural Equation Modeling) PLS (Partial Least Square) atau SEM PLS. Pengumpulan data dan informasi dilakukan melalui pengisian kuesioner menggunakan 5 skala likert. Teknik pengolahan dan analisis data menggunakan uji validitas dan realibilitas, analisis deskriptif, analisis komparatif, serta pengujian model dengan SEM PLS.

Pada Gambar 1 terlihat bahwa penelitian ini dimulai dari dua cabang Restoran Karimata (TMII dan Sentul) yang memiliki tingkat turnover yang berbeda. Jumlah turnover karyawan TMII lebih banyak dibandingkan Sentul. Semakin banyak jumlah karyawan yang keluar, kinerja perusahaan juga dapat semakin menurun. Salah satu tindakan preventif yang dapat dilakukan perusahaan ialah melalui diteksi dini kondisi kepuasan kerja, keterikatan karyawan, dan intensi keluar. Analisis diawali dengan mengetahui ada tidaknya perbedaan yang signifikan dari masing-masing variabel (kepuasan kerja, keterikatan karyawan, dan intensi keluar) di kedua cabang Karimata, meneliti pengaruh antar variabel, dan indikator apa saja yang berkontribusi signifikan terhadap masing-masing variabel. Indikatorindikator yang digunakan pada variabel kepuasan kerja adalah gaji, pekerjaaan, kesempatan promosi, penyelia, dan rekan kerja, variabel keterikatan karyawan yaitu kesungguhan, dedikasi, dan penghayatan, serta variabel intensi keluar yakni niat untuk keluar, mencari pekerjaan lain, danerfikir berfikir berhenti. Selanjutnya, hasil analisis dapat menjadi informasi penting bagi manajemen untuk mengambil tindakan dalam membuat kebijakan. Maka, berdasarkan pada uraian di atas, hipotesis yang diajukan pada penelitian ini yaitu sebagai berikut: 
H1: kepuasan kerja berpengaruh secara positif terhadap keterikatan karyawan

$\mathrm{H} 2$ : kepuasan kerja berpengaruh secara negatif terhadap intensi keluar karyawan

H3: keterikatan karyawan berpengaruh secara negatif terhadap intensi keluar karyawan

\section{HASIL}

\section{Gambaran Umum Restoran Karimata}

Restoran Karimata merupakan usaha keluarga yang didirikan oleh Agung Eko Widodo pada tanggal 22 Desember 2008. Restoran ini pertama kali didirikan di Desa Pasir Maung, Cijayanti, Sentul Selatan. Pada tanggal 21 Agustus 2010 lokasi restoran ini dipindahkan ke depan tol Sentul Selatan 2 (Bogor Ring Road), Grand Sentul City, Bogor karena dinilai lebih strategis untuk menjangkau calon konsumen, yakni pekerja kantoran dan keluarga yang berwisata. Pada 11 Maret 2012 kemudian dibuka cabang di TMII, Jakarta Timur.
Restoran Karimata dikelola dengan manajemen keluarga dan memiliki struktur organisasi yang pendek. Semua keputusan strategis dalam bidang pemasaran, produksi, sumber daya manusia, dan keuangan dipegang oleh pemilik. Sedangkan, kegiatan operasional dan pengaturan kerja karyawan dijalankan oleh seorang supervisor. Para karyawan bertangungjawab kepada supervisor untuk kemudian dilaporkan kepada pemilik perusahaan. Jabatan struktural dalam Restoran Karimata TMII meliputi owner, supervisor, captain, cashier, waiters, public area, checker, gudang, koki, grill, electric maintainance, bartender, dan steward. Jabatan struktural dalam Restoran Karimata Sentul terdiri dari owner, supervisor, cashier, waiters, checker, gudang, koki, grill, electric maintainance, bartender, dan steward.

Jam operasional perusahaan mulai dari jam 10.00 sampai jam 21.00 wib (last order). Restoran libur setiap hari Senin (kecuali hari Senin adalah hari libur nasional). Shift kerja dibagi menjadi dua, yaitu shift pagi mulai dari jam 08.00 sampai jam 16.00 dan shift siang mulai dari jam 12.00 sampai jam 21.00.

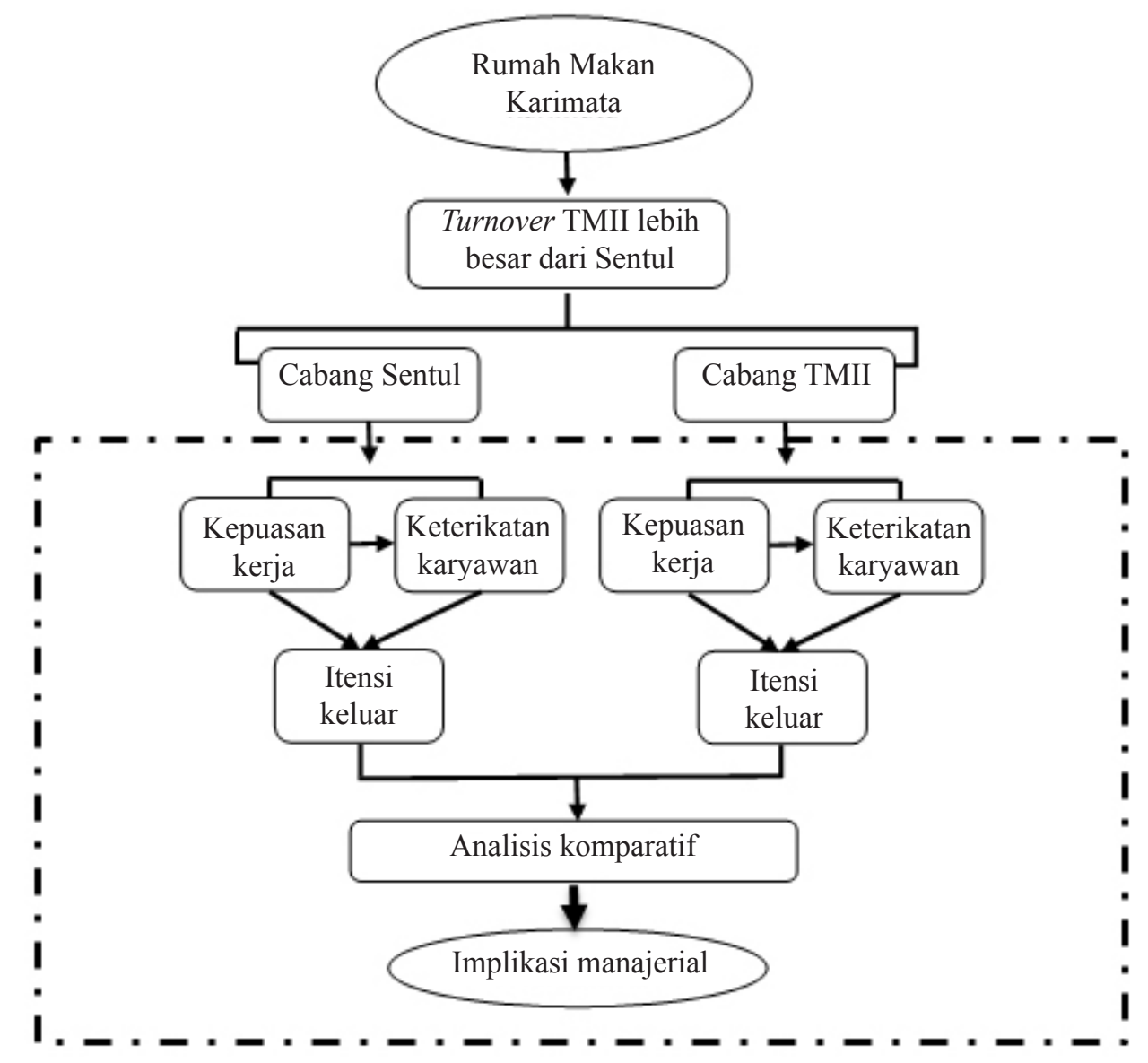

Gambar 1. Kerangka pemikiran penelitian 


\section{Karakteristik Responden}

Karakteristik responden di TMII mayoritas karyawan terdiri dari $75 \%$ laki-laki, $46 \%$ berusia $\leq 25$ tahun, $45 \%$ berpendidikan SMA/SMK, 49\% dan Sarjana 3\% lama bekerja pada rentang 1-5 tahun, dan 20\% sebagai waitress. Sedangkan pada cabang Sentul, mayoritas mayoritas karyawan terdiri dari 79\% laki-laki, 49\% berusia $\leq 25$ tahun, $78 \%$ berpendidikan SMA/SMK, $61 \%$ lama bekerja 1-5 tahun, dan 34\% sebagai bagian waiters. Menurut Kreitner dan Kinicki (2004), masa kerja yang lama akan cenderung membuat seorang pegawai lebih merasa betah. Hal ini antara lain disebabkan karyawan telah beradaptasi dengan lingkungan yang cukup lama sehingga akan merasa nyaman dengan pekerjaannya. Jabatan karyawan Restoran Karimata baik di cabang TMII maupun Sentul didominasi oleh Service/Waiters dengan presentase sebesar $20 \%$ di TMII dan 34\% di Sentul. Hal ini dikarenakan waiters yang berhadapan langsung melayani konsumen jumlahnya harus disesuaikan dengan rata-rata jumlah konsumen yang datang. Berdasarkan asal daerah, karyawan Karimata TMII cenderung berasal dari berbagai daerah yang didominasi dari Bogor sebesar 16\%. Sebaliknya, karyawan Karimata Sentul sebanyak 91\% berasal dari Kabupaten Bogor. Hal ini berarti Karimata TMII lebih banyak mempekerjakan pendatang, sedangkan Karimata Sentul lebih banyak warga sekitar restoran

\section{Respon Karyawan terhadap Job Satisfaction, Employee Engagement dan Turnover Intention}

Hasil penelitian, secara deskriptif respon karyawan TMII terhadap job satisfaction menunjukkan 52,1\% kurang puas pada gaji, 59,0\% puas pada pekerjaan, $45,1 \%$ puas pada kesempatan promosi, $55,9 \%$ kurang puas pada penyelia dan $62,7 \%$ sangat puas pada rekan kerja. Respon terhadap employee engagement menunjukkan 55,9\% sungguh-sungguh dalam bekerja, 40,7\% berdedikasi dan 48,0\% memberikan penghayatan biasa saja. Respon terhadap turnover intention menunjukkan mayoritas karyawan memberikan respon biasa saja pada niat keluar 50,5\%, mencari pekerjaan lain 31,6\% dan berfikir berhenti 42,4\%. Ketidakpuasan yang terjadi di TMII termasuk kedalam teori hygiene factor yang berhubungan dengan konteks kerja secara eksternal. Umumnya karyawan mengharapkan bahwa faktor tertentu akan memberikan kepuasan kerja apabila dipenuhi dan dapat menimbulkan ketidakpuasan apabila tidak dipenuhi (Herzberg, 1987). Teori ini menghubungkan kondisi di sekitar pekerjaan dilaksanakan seperti kondisi kerja, pengupahan, keamanan, kualitas pengawasan, dan hubungan dengan orang lain, teori ini termasuk kedalam motivasi merupakan dorongan internal yang bergantung pada kebutuhan seseorang untuk mencapai tujuan. Untuk kasus di TMII adalah pada gaji dan penyelia yang diasumsikan gaji tidak sesuai dengan pekerjaan yang dibebankan dan penyelia terbebani pekerjaan yang over sehingga penyelia lebih mementingkan pekerjaannya. Akan tetapi, 59,0\% puas pada pekerjaan yang artinya karyawan bisa melewati atau memenuhi jobdesknya. Jika melihat respon terhadap engagement yang cukup baik maka hal ini sudah sejalan dengan teori (Vazirani, 2007) yang mengatakan bahwa tidak ada karyawan yang engaged apabila ia tidak merasa puas dengan pekerjaannya. Oleh karena itu, sangat penting untuk organisasi melihat apakah pekerjaan tersebut sesuai dengan tujuan karir yang disukai oleh karyawan tersebut.

Sementara itu, dilihat dari turnover intention menunjukkan mayoritas karyawan memberikan respon biasa saja pada niat keluar, mencari pekerjaan lain dan berfikir berhenti. Ini dapat diasumsikan bahwa semakin banyak aspek-aspek atau nilai nilai dalam perusahaan sesuai dengan dirinya maka semakin tinggi tingkat kepuasan yang dirasakan. Hal ini sejalan dengan discepancy theory yang menyatakan bahwa kepuasan dapat tercapai bila tidak ada perbedaan antara apa yang seharusnya ada (harapan, kebutuhan, nilai-nilai) dengan apa yang menuntut perasaan atau persepsinya telah diperoleh atau dicapai melalui pekerjaan (Wexley dan Yukl, 1992).

Respon karyawan Sentul terhadap job satisfaction menunjukkan $36,6 \%$ puas dan 28,15 sangat puas pada gaji, $48,9 \%$ puas pada pekerjaan, $36,8 \%$ puas dan $36,3 \%$ sangat puas pada kesempatan promosi, $44,4 \%$ puas pada penyelia dan $58,5 \%$ sangat puas pada rekan kerja. Respon terhadap employee engagement menunjukkan 41,4\% kesungguhan yang biasa saja, $77,5 \%$ berdedikasi dan $46,2 \%$ memiliki penghayatan biasa saja. Respon terhadap turnover intention menunjukkan mayoritas karyawan memberikan respon tidak memiliki niat keluar $67,2 \%$, tidak mencari pekerjaan lain $50,3 \%$ dan tidak berfikir berhenti $73,7 \%$. Respon Job Satisfaction di Sentul kebalikan dari TMII dimana rata-rata menunjukan kepuasan terhadap indikator Job Satisfaction jika dilihat dari hasil wawancara pengambilan data karyawan Sentul memang cukup loyal terhadap owner sehingga ada 
hubungan di luar indikator yang memang melatar belakangi. Selain itu, loyalitas adalah cerminan dari sikap karyawan yang mampu mengoptimalkan kemampuan yang dimiliki, bertanggungjawab terhadap tugas yang diberikan, disiplin serta jujur dalam bekerja (Poerwopoespito, 2000). Maka, diasumsikan loyalitas karyawan berhubungan kepuasan kerja karyawan sehingga memengaruhi keadaan emosional karyawan yang dirasakan karyawan terhadap pekerjaannya serta perusahaan dapat memberikan fasilitas yang dapat memuaskan kebutuhan karyawan di perusahaan tersebut. Jika kepuasan karyawan terjadi, maka karyawan akan merasakan perasaan positif terhadap perusahaannya, yang sering diwujudkan dalam tanggung jawab karyawan terhadap pekerjaan yang dihadapi atau ditugaskan kepadanya dilingkungan kerjanya (Martoyo ,2000). Hal ini juga melatarbelakangi kenapa employee engagement di Sentul sangat engage dibandingkan TMII sehingga berpengaruh ke rendahnya angka turnover intention dan lebih prefer untuk tetap tinggal di Sentul.

\section{Evaluasi Model SEM}

Pengujian dan evaluasi model dilakukan dengan menggunakan SEM PLS. Pada model yang digunakan dalam penelitian terdapat 3 variabel laten yaitu job satisfaction dengan 5 indikator (X11 - Gaji, X12 - Pekerjaan , X13 - Kesempatan Promosi, X14 Penyelia, X15 - Rekan Kerja), employee engagement dengan 3 indikator (Y11 - Kesungguhan, Y12 Dedikasi, Y13 - Penghayatan), turnover intention dengan 3 indikator (Y21 - Niat Keluar, Y22 - Mencari
Pekerjaan Lain, Y23 - Berfikir Berhenti). Pengujian data dengan menggunakan SEM dilakukan secara dua tahap, yakni penetapan model pengukuran (outer model) dan penetapan model struktural (inner model) (Ghozali, 2008). Evaluasi model pengukuran setidaknya menghasilkan loading factor pada seluruh indikator reflektif bernilai $>0,5$ sebagai kriteria, sedangkan penetapan model struktural dilakukan untuk menganalisis pengaruh antar variabel laten dengan melihat nilai t-statistik dan R-square. Hasil evaluasi model di TMII seperti Gambar 2.

Berdasarkan hasil evaluasi, job satisfaction karyawan TMII berpengaruh terhadap turnover intention sebesar -0,568. Artinya, semakin meningkat job satifaction maka turnover intention akan semakin menurun. Job satisfaction juga memiliki pengaruh pada employee engagement sebesar $-0,886$. Tanda negatif menunjukkan bahwa job satisfaction dan employee engagement tidak memiliki hubungan yang searah sesuai dengan teori yang menyatakan bahwa peningkatan job satisfaction akan meningkatkan employee engagement. Dalam kasus ini, job satisfaction cenderung rendah namun employee engagement cenderung tinggi. Hal ini dapat dijelaskan dengan pengujian struktural yang menunjukkan nilai R-square sebsar 78,5\%, artinya keragaman employee engagement yang dapat dijelaskan oleh model sebesar $78,5 \%$ sedangkan sisanya $21,4 \%$ dijelaskan faktor lain diluar model. Employee engagement pada cabang ini juga tidak memiliki pengaruh terhadap turnover intention. Hasil evaluasi model pada cabang Sentul selengkapnya pada Gambar 3.

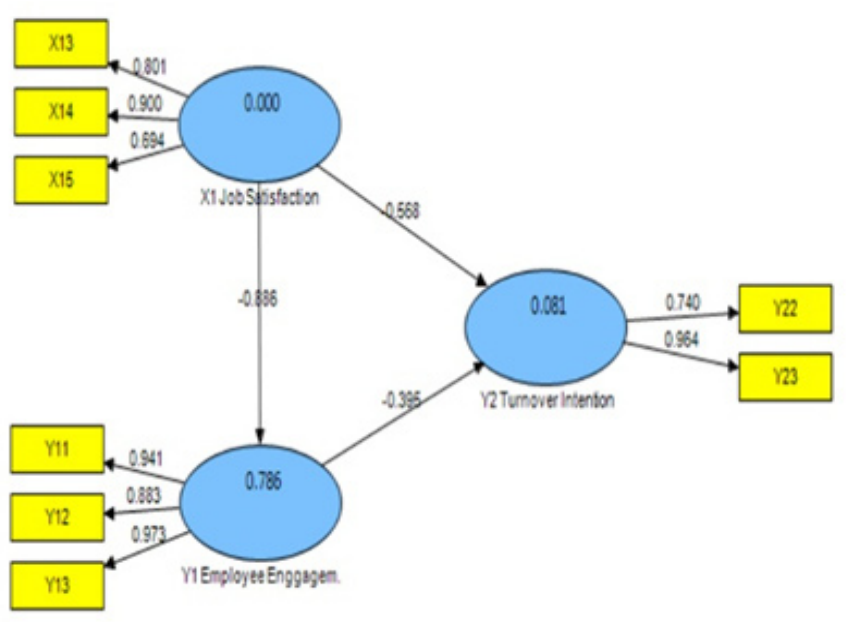

(b) Model Akhir

(a) Model Awal

Gambar 2. Penetapan model pengukuran TMII 


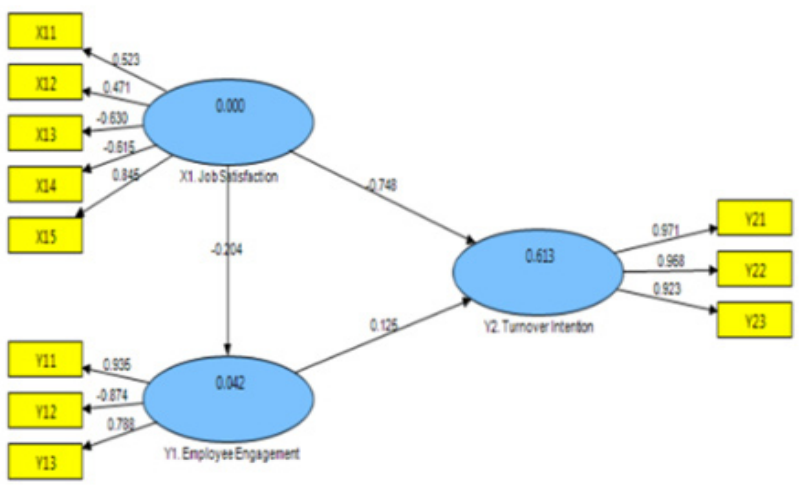

(a ) Model Awal

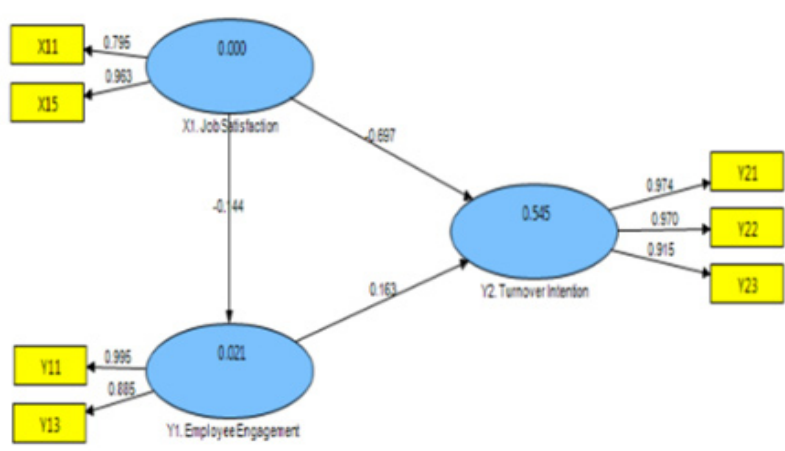

( b ) Model Akhir

Gambar 3. Penetapan model pengukuran Sentul

Berdasarkan hasil evaluasi, job satisfaction karyawan Sentul berpengaruh terhadap turnover intention sebesar -0,697. Artinya, semakin meningkat job satifaction maka turnover intention akan semakin menurun. Namun, job satisfaction tidak memiliki pengaruh yang signifikan terhadap employee engagement. Begitu juga dengan employee engagement pada cabang ini juga tidak memiliki pengaruh yang signifikan terhadap turnover intention. Hasil pengujian struktural yang menunjukkan nilai R-square sebesar 21,1\%, yang artinya keragaman employee engagement yang dapat dijelaskan oleh model hanya sebesar $21,1 \%$, sedangkan sisanya $78,9 \%$ dijelaskan faktor lain di luar model. Sama seperti di TMII, berdasarkan hasil wawancara, employee engagement karyawan di Sentul sangat dipengaruhi oleh owner. Karyawan memiliki kedekatan dan loyal terhadap owner sehingga mereka merasa terikat dengan restoran. Model struktural Turnover Intention menghasilkan nilai R-square $54,5 \%$ artinya keragaman Turnover Intention yang mampu dijelaskan oleh model sebesar 54,5\% sedangkan sisanya 45,5\% dijelaskan oleh faktor lain diluar model.

\section{Analisis Komparatif Hasil Evaluasi}

Berdasarkan pengujian model yang telah dilakukan terhadap pengaruh job satisfaction, employee engagement, dan turnover intention, maka hasil yang diperoleh perbandingan seperti pada Tabel 1. Kepuasan kerja di TMII berpengaruh terhadap keterikatan karyawan dan intensi keluar. Meskipun nilai kepuasan kerja cenderung rendah, namun karyawan TMII masih memiliki keterikatan yang kuat terhadap perusahaan.
Rendahnya tingkat kepuasan karyawan pada cabang ini sangat dipengaruhi oleh gaji dan penyelia. Secara umum, karyawan TMII memiliki etos kerja yang tinggi pada setiap pekerjaan yang diberikan berdasarkan sistem rotasi pekerjaan (promosi). Atas kerja keras yang dilakukan tersebut, karyawan TMII merasa belum mendapatkan apresiasi yang sebanding secara finansial. Sementara itu, kepuasan kerja yang berpengaruh terhadap intensi keluar memiliki tanda negatif, yang artinya semakin tinggi kepuasan kerja maka intensi keluar pada cabang TMII akan semakin menurun. Di sisi lain, keterikatan karyawan pada cabang ini tidak menunjukkan adanya pengaruh terhadap intensi keluar.

Pada cabang sentul hanya kepuasan kerja yang berpengaruh terhadap intensi keluar. Artinya, semakin tinggi kepuasan kerja maka intensi keluar akan semakin rendah. Tingginya kepuasan kerja di Sentul sangat berkorelasi dengan semua indikator yang digunakan dalam penelitian, yakni gaji, pekerjaan, kesempatan promosi, penyelia dan rekan kerja. Sementara kepuasan kerja terhadap keterikatan karyawan dan keterikatan karyawan terhadap intensi keluar tidak menunjukkan adanya pengaruh. Engagement karyawan di Sentul dipengaruhi oleh faktor lain diluar dari variabel yang digunakan dalam penelitian, yakni kedekatan dengan owner. Selain itu, karakteristik karyawan Karimata pada umumnya merupakan Generasi Y. Menurut Nurhasan (2017), kepuasan kerja Generasi Y tidak berpengaruh secara signifikan terhadap loyalitas. Menurut Anggraini et al. (2016), generasi Y memiliki aspek baik secara emosional, fisik, maupun penghayatan yang tinggi. 
Tabel 1. Perbandingan Pengaruh Variabel pada Cabang TMII dan Sentul

\begin{tabular}{lcc}
\hline Pengaruh Variabel & \multicolumn{2}{c}{ Cabang RM. Karimata } \\
\cline { 2 - 3 } & TMII & Sentul \\
\hline job satisfaction $\rightarrow$ employee engagement & $\sqrt{ }$ \\
job satisfaction $\rightarrow$ turnover intention & $\sqrt{ }$ \\
employee engagement $\rightarrow$ turnover intention & - & - \\
\hline
\end{tabular}

Kajian penelitian ini dilakukan beradasarkan berbagai teori yang mengungkapkan adanya hubungan dan pengaruh yang positif antara kepuasan kerja terhadap keterikatan karyawan dan intensi keluar. Kepuasan kerja dinyatakan sebagai pertanda awal untuk menimbulkan komitmen organisasi. Beberapa penelitian dalam beberapa tahun terakhir oleh Demicco dan Reid (1988), Johnson et al. (1990), Lum et al. (1998) dan Chen (2007) juga menyimpulkan bahwa semakin tinggi kepuasan kerja yang dirasakan karyawan maka akan semakin tinggi komitmennya pada perusahaan. Namun hal tersebut berbanding terbalik dengan kasus penelitian karena kepuasan kerja yang dirasakan karyawan di TMII dan Sentul tidak memberikan pengaruh yang positif terhadap keterikatan pada perusahaan. Berdasarkan hasil wawancara terhadap para responden menujukkan bahwa keterikatan karyawan pada perusahaan ini sangat dipengaruhi oleh pemilik perusahaan. Namun, dalam penelitian ini owner perusahaan tidak menjadi indikator pengukuran.

Sementara itu, hasil penelitian pada kedua cabang menunjukkan hasil yang signifikan dan positif terhadap hubungan antara kepuasan kerja pada intensi keluar. Hasil ini senada dengan berbagai penelitian yang telah dilakukan sebelumnya oleh Kalbers dan Fogarty (1995), Passewark dan Strawser (1996) dan Mobley (1986) yang menyatakan bahwa kepuasan kerja penting bagi perusahaan karena dapat meningkatkan produktivitas dan menurunan keinginan untuk keluar. Apabila karyawan memiliki kepuasan kerja yang tinggi terhadap pekerjaanya, maka karyawan tersebut tidak akan memiliki pemikiran-pemikiran untuk pindah kerja atau mencari pekerjaan lain. Pendapat ini juga senada dengan hasil penelitian Alam (2013) yang menyatakan bahwa karyawan yang merasa puas dengan apa yang didapatkannya dari perusahaan maka akan bertahan dan mampu bekerja secara produktif.

\section{Implikasi Manajerial}

Implikasi manajerial dibuat berdasarkan hasil penelitian yang menunjukkan adanya kontribusi besar terhadap kepuasan kerja, keterikatan karyawan, dan intensi keluar. Indikator kepuasan kerja yang berkontribusi signifikan pada cabang TMII adalah penyelia. Cara sederhana yang dapat dilakukan adalah memberikan nasihat dan masukkan kepada penyelia atas cara penyampaian informasi, kritik, ataupun saran kepada karyawan agar tidak terjadi kesalahpahaman. Cara lainnya adalah dengan mengadakan acara kebersamaan seperti makan siang bersama saat hari libur restoran atau acara nonton bola bersama. Program tersebut diharapkan dapat meningkatkan kebersamaan dan komunikasi tim sehingga tercipta suasana kekeluargaan yang lebih nyaman. Kurniawan (2000) mengungkapkan bahwa iklim komunikasi yang kondusif berpengaruh signifikan terhadap kepuasan kerja karyawan. Jenis komunikasi yang kondusif yang dapat dilakukan adalah komunikasi horizontal yang bersifat koordinasi. Menurut Yulianto (2017), komunikasi horizontal lebih dapat menimbulkan kepuasan kerja karyawan. Manajemen juga dapat mengadakan acara liburan atau jalan-jalan rutin untuk meningkatkan kedekatan antar karyawan. Adanya suasana yang lebih akrab dan hubungan kekeluargaan yang lebih erat menjadikan karyawan akan lebih mudah bekerjasama untuk menyelesaikan semua pekerjaan dan menurunkan keinginan karyawan untuk keluar dari perusahaan, karena faktor lingkungan kerja yang tidak nyaman. Program tersebut juga ditujukan untuk indikator rekan kerja yang memiliki kontribusi yang terendah dan level pelaksanaannya saat ini pun juga masih rendah.

Pada cabang Sentul, terdapat dua indikator yang memiliki kontribusi signifikan terbesar terhadap kepuasan kerja yakni rekan kerja dan gaji. Karyawan Sentul menunjukkan respon yang setuju pada semua indikator yang digunakan. Level pelaksanaan kedua indikator pun juga sudah cukup baik. Namun, sebaiknya manajemen tetap mempertahankan kebijakan pemberian upah dan insentif pada karyawan, seperti 
berdasarkan banyaknya pekerjaan dan lama bekerja. Karyawan Sentul pun rutin berinisiatif mengadakan acara kebersamaan, seperti jalan-jalan setiap tahunnya. Oleh karena itu, sebaiknya ke depannya pihak manajemen perlu mengambil inisiatif terlebih dulu dalam merencanakan acara kebersamaan tersebut agar karyawan merasa lebih senang, karena mengetahui manajemen peduli terhadap mereka.

Peningkatan keterikatan karyawan pada kedua cabang dapat dilakukan melalui komunikasi yang lebih baik pada karyawan untuk meningkatkan kecintaan dan menumbuhkan rasa tanggung jawab yang lebih besar pada pekerjaan. Kegiatan briefing secara rutin yang dijadwalkan waktunya dapat dilakukan di kedua lokasi restoran mengingat hal tersbut memang jarang dilaksanakan. Kegiatan tersebut akan lebih baik jika briefing dilakukan per bagian atau unit kerja, sehingga fokus diskusi dan pengarahannya. Hal tersebut dikarenakan tiap karyawan di tiap unit kerja memiliki permasalahannya masing-masing. Selain itu, manajemen juga dapat meningkatkan kondisi lingkungan dan suasana kerja yang lebih memadai agar karyawan merasa lebih nyaman dalam bekerja.

Hasil penelitian menunjukkan bahwa intensi keluar pada kedua cabang sangat dipengaruhi oleh kepuasan kerja. Untuk menghindari terjadinya pemikiran untuk keluar dan niat keluar maka manajemen harus meningkatkan kepuasan kerja melalui program yang dapat meningkatkan kepuasan terhadap indikatorindikator yang berkontribusi signifikan terhadapnya, seperti yang telah disebutkan pada poin 1. Peningkatkan program-program tersebut diharapkan intensi keluar karyawan dapat dihindari. Pelaksanaan program yang direkomendasikan pada implikasi manajerial, pada dasarnya perlu dilakukan pada kedua tempat agar tidak menimbulkan kecemburuan sosial antar cabang. Namun, dalam pelaksanaannya masing-masing cabang perlu diberikan penekanan yang berbeda sesuai dengan kebutuhan.

\section{KESIMPULAN DAN SARAN}

\section{Kesimpulan}

Indikator yang berkontribusi signifikan terhadap kepuasan kerja karyawan Restoran Karimata cabang TMII adalah kesempatan promosi, penyelia, dan rekan kerja sedangkan pada cabang sentul adalah gaji dan rekan kerja. Indikator yang berkontribusi signifikan terhadap keterikatan karyawan di TMII adalah kesungguhan, dedikasi, dan penghayatan, sedangkan pada cabang sentul adalah kesungguhan dan penghayatan. Indikator yang berkontribusi signifikan pada intensi keluar pada TMII adalah mencari pekerjaan lain dan berfikir berhenti. Sedangkan pada sentul adalah niat keluar, mencari pekerjaan lain, dan berfikir berhenti.

Perbedaan yang signifikan terjadi pada kepuasan kerja antara di TMII dan Sentul. Kepuasan kerja di Sentul lebih tinggi dibandingkan di TMII. Sedangkan pada keterikatan karyawan dan intensi keluar tidak menunjukkan perbedaan yang signifikan antara kedua tempat. Kepuasan kerja pada cabang TMII dan Sentul tidak berpengaruh terhadap keterikatan karyawan. Keterikatan karyawan pada kedua cabang tersebut juga tidak berpengaruh terhadap intensi keluar. Sedangkan kepuasan kerja pada keduanya berpengaruh terhadap intensi keluar.

Rekomendasi untuk meningkatkan kepuasan kerja, keterikatan karyawan dan menurunkan intensi keluar pada cabang sentul adalah pemberian gaji yang sesuai dengan lama bekerja dan kesungguhan karyawan dalam melakukan setiap pekerjaan. Sedangkan pada cabang TMII, manajemen dapat meningkatkan kegiatan kebersamaan untuk meningkatkan kerjasama tim dan jiwa kepemimpinan yang lebih baik.

\section{Saran}

Hasil penelitian menunjukkan bahwa keterikatan karyawan memiliki kecenderungan yang hampir sama dan tidak berpengaruh signifikan terhadap intensi keluar di kedua lokasi restoran, sehingga ke depannya perlu dibedakan respon keterikatan karyawan antara supervisor dan line-level employees. Selain itu, model keterikatan karyawan menghasilkan nilai keragaman yang berbeda pada Restoran Karimata Cabang TMII dan Sentul. Untuk itu, penelitian ini dapat dilanjutkan dengan melakukan pengujian berdasarkan teori dari pakar lainnya agar diperoleh gambaran indikator yang lebih berkontribusi terhadap keterikatan karyawan di Restoran Karimata. Saran lainnya adalah melakukan kajian indikator yang berkontribusi pada keterikatan karyawan berdasarkan teori dari pakar lainnya. Hal ini dilakukan sebagai upaya untuk meningkatkan engagement karyawan. 


\section{DAFTAR PUSTAKA}

Alam KH, Musadieq AM, Susilo H. 2013. Pengaruh gaya kepemimpinan terhadap motivasi kerja dan kinerja (studi pada Karyawan PT. PLN Persero APJ Malang). Jurnal Administrasi Bisnis 1(2): 141-149

Alam M. 2010. Level of Job Satisfaction and Intent to Leave Among Malaysia, Ed ke-3. Jakarta: Ghalia Indonesia.

Anggriani L, Astuti SE, Prasetya A. 2016. FaktorFaktor yang Memengaruhi Keterikatan karyawan Generasi Y (Studi Pada Karyawan PT Unilever Indonesia Tbk-Surabaya). Jurnal Administrasi Bisnis 37(2): 183-191

Badan Pusat Statistik. 2015. Statistik Restoran Rumah Makan 2015. https://www. bps.go.id/publication/2017/01/25/ e58e9accf6daff02387564b1/statist ik-restoranrumah-makan-2015.html. [diakses 14 Mar 2019].

Badan Pusat Statistik. 2017. Statistik Restoran Rumah Makan 2016. https://www.bps.go.id/publication. html?Publikasi\%5BtahunJudul\%5D=2017\&Pu blik asi $\% 5$ BkataKunci $\% 5 \mathrm{D}=\& \mathrm{yt} 0=$ Tampilkan $\&$ page $=8$. [24 Feb 2019].

Baumruk R, Gorman B. 2006. Why managers are crucial to increasing engagement. Journal Strategic HR Review $5: 24-27$

Buckingham M, Coffman C. 2005. First, Break all the Rules. Sudney: Great Britain

Cellucci AJ, avid LDV. 1978. Measuring Managerial Satisfaction: A Manual for the MJSQ, Technical Report II(Center for Creative Leadership) 34:10-37.

Chen JP, Jaggi BL. 2000. The Association between independent non-executive directors, family control, and financial disclosure. Journal of Accounting and Public Policy 19: 285-310.

DeMicco JF, Reid RD. 1988. Older Workers: A Hiring Resources for The Hospitality Industry. Cornell Hotel and Restaurant Administration Quartely, May. Business and Economic Research Journal 3(2):56-62.

Ghozali I. 2008. Generalized Structured Component Anolysis (GSCA). Semarang: Badan Penerbit Universitas Diponegoro.

Herzberg F. 1987. One more time: how do you motivate employees? Harvard Business Review 81(1):8796.
Johnson. 1990. The impact of conflict resolution training on middle school students. The Journal of Social Psychology 137: 11-20.

Kalbers, Lawrence P, Fogarty, Timothi J. 1995. Profesionalism and Its Consequences: A Study of Internal Auditors. Auditing: A Journal of Practice and Theory 14:64-86.

Kementerian Keuangan Badan Kebijakan Fiskal.2019. http://webcache.googleusercontent.com/ search?q=cache:eorjZWrT9IIJ:www.fiskal. kemenkeu.go.id/dw-kontenview.asp\%3Fid\% 3D20130508112714655687319+\&cd=1\&hl $=\mathrm{id} \& \mathrm{ct}=\mathrm{clnk} \& \mathrm{gl}=\mathrm{id}[14$ Mar 2019]

Kreitner R, Kinicki A. 2004. Organizational Behavior. Boston: McGraw Hill.

Lum. 1998. Explaining nursing turnover intent: job satisfaction, pas satisfaction, or organizational commitment. Journal of Organizational Behaviour 19(3): 305-320.

Macey WH, Schneider B, Barbera KM, Young SA. 2009. Talent management essentials. employee engagement: Tov vxols for analysis, practice, and competitive advantage. Journal of Industrial and Organizational Psychology 1. 3-30.

Mangkunegara AA. 2013. Manajemen Sumber Daya Manusia Perusahaan. Bandung: PT. Remaja Rosdakarya.

Margaretha M, Saragih S. 2008. Keterikatan karyawan: upaya peningkatan kinerja organisasi. Jurnal: The 2nd national Conference UKWMS.3-15.

Martoyo S. 2000. Manajemen Sumber Daya Manusia. Yogjakarta: BPFE.

Mobley WH. 1986. Pergantian Karyawan: Sebab, Akibat dan Pengendaliannya. Imam N penerjemah. Jakarta: PT Pustaka Binaman Pressindo.

Mobley WH. Horner SO and Hollingsworth AT. 1978. An evaluation of precursors of hospital employee turnover. Journal of Applied Psychology 63(4): 408-414.

Muhyi AH. Muttaqin Z dan Nirmalasari H. 2016. HRplan \& strategy Strategi jitu pengembangan sumber dayamanusia. Jakarta: Raih Asa Sukses.

Nurhasan R. 2017. Kepuasan Kerja dan Loyalitas Generasi-Y. Jurnal Wacana Ekonomin 17(1):111.

Passewark MF. Strawser JR. 1996. The Determinants and Outcomes Associated with Job Insecurity in a Professional Accounting Environment. Behavioral Research in Accounting 1(8): 91- 
110.

Poerwopoespito. 2000. Mengatasi Krisis Manusia Di Perusahaan. Jakarta: PT.Gramedia Widiasarana Indonesia.

Rachmatan R, Kubatini S. 2018. Hubungan antara keterikatan kerja dengan intensi keluar kerja pada karyawan swalayan di Banda Aceh. Jurnal Psikogenesis 6 (1): 1-10.

Roseman E. 1981. Managing Turnover: A Positive Approach. New York: Amacom.

Schaufeli BW, Salanova M, Gonzalez-Roma V, Bakker BA. 2002. The measurement of engagement and burnout: A confirmative analytic approach. Journal of Happiness Studies 3(1): 71-92.

Schaufeli WB, Salanova M, Gonzalez-Roma V and Bakker AB. 2002. The measurement of engagement and burnout: A confirmative analytic approach. Journal of Happiness Studies 3(1): 71-92.

Siddiqi MA. 2013. Examining work engagement as aprecursor to turnover intentions of service employees. Business and Management 5(4): 118-132.

Vazirani N. 2007. Keterikatan karyawan. Working Paper Series, SIES College of Management Studies 1-17.

Wexley NK, Yukl AG. 1992. Organizational Behavior And Personnel Psychology. Cetakan Ke 2. Jakarta: Rineka Cipta.

YamazakiaY and Petchdee S. (2015). Turnover Intention Organizational Commitment and Specific Job Satisfaction among Production Employees in Thailand. Journal of Business and Management 4 (4): 22-38. 